\title{
Quality Management Approaches in Libraries and Information Services
}

\author{
PAO-NuAn HSIEH; PAO-LONG CHANG; KuEN-HORNG LU \\ Dept. and Graduate Institute of Library and Information Science, National Taiwan University, Taipei; \\ Institute of Business and Management; National Chiao Tung University, Taipei; \\ Dept. of Industrial Engineering and Management; National Kaohsiung Institute of Technology, \\ Kaohsiung; \\ Taiwan, Republic of China
}

The increasing expectations of users for better services have motivated libraries to view quality management as an effective means of incorporating quality improvement into their related services. Effectively implementing quality management in libraries requires an understanding of applying appropriate quality management concepts and techniques.
This article reviews the quality management tools and techniques developed over the last five decades and, then, categorises them into three broad approaches. In addition, a framework of quality management approaches and techniques is developed and applied to assess and improve the service quality of libraries and information services.

\section{Introduction}

The increasing expectations of users have challenged libraries to improve their quality of services. Limited by increasingly tighter budgetary restrictions, library managers feel more pressure to fully exploit available resources. Therefore, several libraries and information services have adopted quality management practices in recent years. Among the various initiatives implemented include ISO 9000 standards (Johannsen 1996), 5S movement (Taipei Municipal Library 1996), and benchmarking (Zairi and Hutton 1995; Garrod and Kinnell 1996; Garrod and Kinnell 1997; Buchanan and Marshall 1996). By adopting quality management, the library's image and service quality can be improved, and librarians can increase productivity while focusing on the customer's needs (Johannsen 1992; Taipei Municipal Library 1996).

Quality management has been extensively applied within the manufacturing industry for over a decade. More recently, the service industry has increasingly emphasised this area. The public sector has also put forward major initiatives to improve quality. Closely examining available quality management techniques in service industries and the public sector reveals their effectiveness and positive impact on the customers. Quality management is increasingly integrated into library services, following their perceived success in manufacturing industries, with particular emphasis on improving service quality.

Libraries have developed numerous programs to fulfil user requirements. In general, libraries concentrate mainly on maintaining administra-

Pao-Nuan Hsieh is Associate Professor at Dept. and Graduate Institute of Library and Information Science, National Taiwan University, 1, Roosevelt Rd., Sec. 4, Taipei, Taiwan, Republic of China. 106. Fax: (+886) 2-23632859, Tel: (+886) 2-23626582, email: pnhsieh@ccms.ntu.edu.tw

Pao-Long Chang is Professor at Institute of Business and Management, National Chiao Tung University, 4F, 114, Sec. 1, Chung Hsiao W. Rd., Taipei, Taiwan, Republic of China. 100. Fax: (+886) 2-23610656, Tel: (+886) 2-23146515 ext. 305, email: paolong@ cc.nctu.edu.tw

Kuen-Horng Lu is Associate Professor at Dept. of Industrial Engineering and Management, National Kaohsiung Institute of Technology, 415, Chien Kung Rd., Kaohsiung, Taiwan, Republic of China. 807. Fax: (+886) 7-3923375, Tel: (+886) 7-3814526 ext. 7117, email: log@cc.nkit.edu.tw 
tive activities, building the collection, and serving the users. Therefore, the functions of a library can be broadly categorised as administrative management, technical services and public services. Administrative management defines the objectives of the library, allocates the resources to achieving such objectives, co-ordinates related activities, and assesses the performance of related services. Technical services largely focus on building the collection and making the collection more accessible for users. The activities of technical services include acquisition, information organisation, and preservation. While all library activities strive to, public services serve the customers most directly. Related activities consist of circulation, reference and access service.

Library services can be viewed as an open system with materials, resources and information needs of customers as input. In other words, the activities involved in providing and using library services are more interrelated than isolated. Figure 1 depicts the interaction within a totally integrated library system. While the library only exists for serving customers, the service delivery system should be user-oriented. Although all functions and activities focus on customers, the direct interaction between library and customers occurs in public services. That is, librarians working in circulation, reference and access service respond and translate the customer's expectations to the technical service department and adminis- trative management. Depending on the ability of public services to accurately interpret customer requirements, all functions of the library can be directed to satisfying the quality requirements and information needs of customers.

Quality management in libraries and information services has received considerable attention, with a majority of those investigations describing quality concepts, quality management principles, related processes, and limitations (Jurow and Barnard 1993; O'Neil 1994; Brophy and Coulling 1996). From the perspective of library services, adopting quality programs increases the effectiveness of the library and satisfies increasingly higher customer expectations. Most quality management-related literature is based on experience drawn from industrial organisations, particularly on the manufacturing of tangible products delivered to the end-user at a later stage. Recent years have witnessed the increasing acceptance of quality management into services-related and non-profit organisations, such as education. Despite the significant level of adaptation within service organisations and the public sector, there exists missing link between quality management principles/tools and the implementation of quality management in libraries and information services. Johannsen (1992) foresaw the risk:

... as the general principles of quality control have originally been developed in private sector and industrial

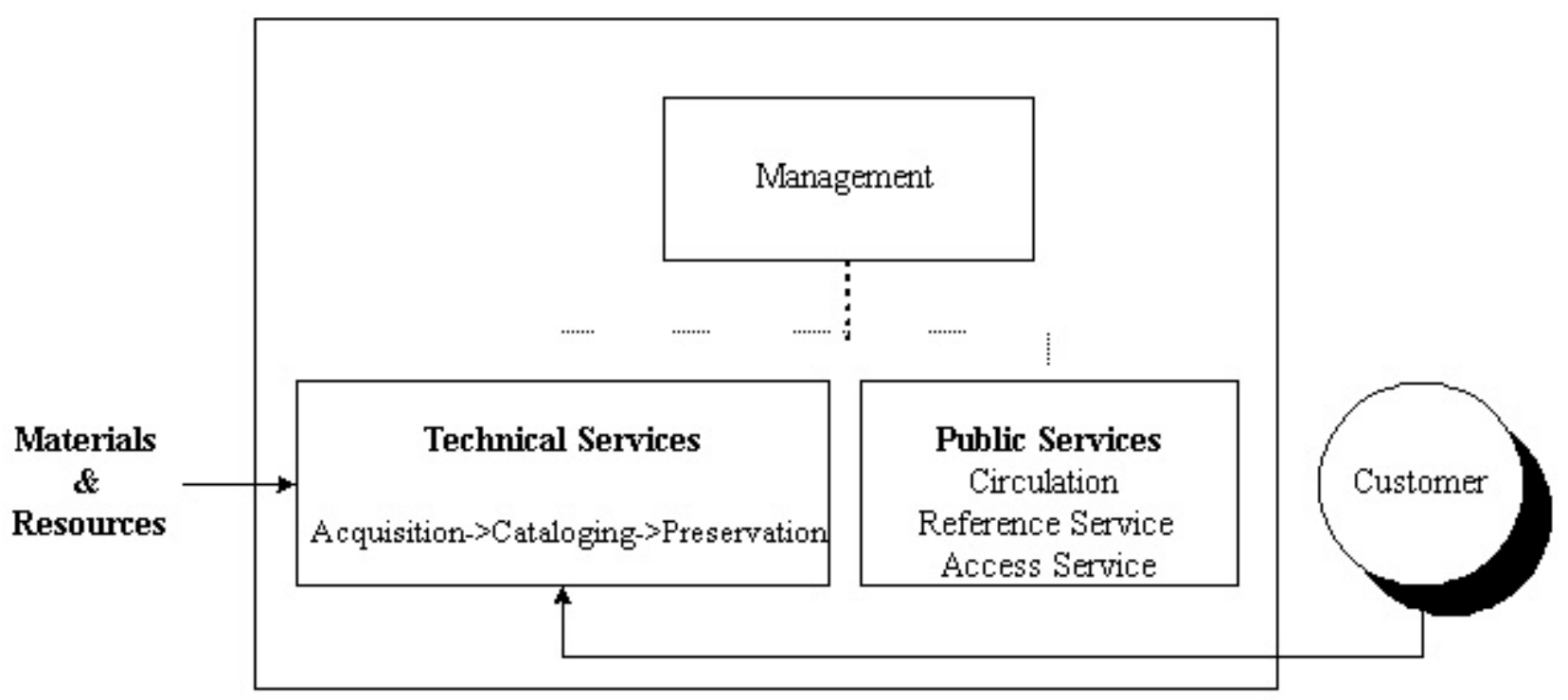

Figure 1: A systemic view of library services 
environments, you may expect problems, when you wish to use those principles to manage quality of an intangible resource, information, in organizations, where structures, culture, management style, business strategies and customers are often very unlike industrial organizations.

Effectively implementing quality management in libraries and information services requires an understanding of the following:

- The unique characteristics of library operations

- The nature of interaction between librarians and customers

- The making of recommendations on the application of appropriate quality management concepts and techniques.

These issues are discussed herein.

\section{Quality management approaches}

Quality management approaches can be categorised broadly into three stages according to the evolution of management control. Management can implement control before an activity commences, while the activity occurs, or after the activity has been completed. Consequently, three types of control are feedforward, concurrent and feedback (Robbins and De Cenzo 1998). The most desirable type of management control is feedforward control that is future-directed and takes place in advance of the actual activity. Feedforward control is advantageous because it allows management to prevent anticipated problems rather than having to cure them later and to avoid wasting resources. Concurrent control, as its name implies, takes place while an activity is in progress. When control is enacted while the activity is being performed, management can correct problems before they become too costly. The most conventional means of control relies on feedback. The feedback control takes place after the activity. However, a disadvantage of this approach is that the damage will have already occurred by the time that the manager has the information to take corrective actions. Consequently, feedforward control is the most economic approach and can meet the requirement of customers, followed by concurrent control and feedback control, respectively. Interestingly, quality management approaches developed and applied to assess and improve product quality can be related to types of management control from the perspective of an open system.

Quality management approaches were originally developed as being product-oriented. Feedback control, an inspection-based quality control approach, was introduced to detect inferior products at the after-production stage. Realising that quality could not be improved by merely inspecting the finished product, subsequent efforts switched the emphasis of quality management from inspection to process control: from feedback control stage to concurrent control stage. The underlying premise regarding quality in the concurrent control stage is that quality is equivalent to meeting or exceeding customer expectations. Manufacturing products that reflect the diverse needs of customers, is more of a function of good design than of good control of a process. Therefore, quality management has gradually shifted to emphasis on the design phase: from concurrent control stage to feedforward control stage. In the following, we discuss the three approaches of quality management and related techniques.

\section{Quality by inspection}

The inspection-based system was perhaps the first scientifically designed quality control system to evaluate quality. The system is applied to incoming raw materials and parts for use as inputs for production and/or finished products. Under this system, some quality characteristics are examined, measured and compared with required specifications to assess conformity. Therefore, the inspection-based system is a screening process that merely isolates conforming from non-conforming products without having any direct mechanism to reduce defects.

Reducing the damage to final products, sampling plans were developed to control product quality. Although an effective technique, a quality control system based on sampling inspection does not directly achieve customer satisfaction and continuous improvement. Producing fewer defects through process improvement is the only means of reducing defects.

\section{Quality by process control}

Defects inevitably add to the production cost and waste resources. Therefore, a business strives for 
zero defects. The quality management system based on sampling inspections has been replaced by the approach of continuously improving the process. This concept, as pioneered by Deming, moves from detecting defects to preventing them and continuing with process improvement to meeting and exceeding customer requirements on a continuous basis. The continuous cycle of process improvement is based on the scientific method for addressing problems, commonly referred to as the Deming cycle. Deming's approach consists of four basic stages: (1) a plan of what to do; (2) do or carry out the plan; (3) study what has done; and (4) act to prevent errors or improve the process. The planning stage consists of studying the current situation, gathering data, and planning for improvement. Related activities include (a) defining the process, its inputs, outputs, customers, and suppliers; (b) understanding customer expectations; (c) identifying problems; (d) testing theories of causes; and (e) developing solutions. In the do stage, the plan is implemented on a trial basis to evaluate a proposed solution and provide objective data. The study stage determines whether or not the trial plan is working correctly and if any further problems or opportunities are identified. In the final stage, act, the final plan is implemented and the improvements become standardised and implemented continuously. This process then returns to the plan stage for further diagnosis and improvement (Evans and Lindsay 1996).

The Deming Cycle can enhance communication between the staff involved and help employees to use the wheel to improve processes. Some of the specific tools used to improve processes are control charts, process capability studies, seven (quality control) tools, seven new (quality management) tools, and seven creativity tools (GOAL/ QPC 1997). However, the appropriate tools must be applied for the specified purpose. For example, cause-and-effect diagrams and process flow charts could be more appropriate during the planning stage of the Deming wheel, whereas control charts may be most appropriate during the stage of checking (Rahman 1995).

\section{Quality by design}

The Deming approach shifted the focus of quality management a step back from inspection to pro- cess control. The approach of quality by design makes a further step back from process to design. By definition, Quality by design implies that quality must be built in early in the development and design stage. By doing so, the final product can satisfy the customers. Two important techniques for designing quality products are quality function deployment (QFD) and Failure Mode and Effect Analysis (FMEA).

Quality function deployment is a structured approach that: (a) identifies and ranks the relative importance of customer requirements; (b) identifies design parameters (or engineering characteristics) that contribute to the customer requirements; (c) estimates the relationship between design parameters and customer requirements and among different design parameters; and (d) sets target values for the design parameters to best satisfy customer requirements. A QFD matrix (or house of quality) is frequently used to translate prioritised customer requirements into identifiable and measurable product specifications and engineering requirements to reduce functional variation and costs, thereby facilitating the decision-makers in making designrelated decisions. Many investigators have successfully applied QFD in product and service design (Guinta and Praizler 1993; Armstrong 1994; Pitman et al. 1996; Lam and Zhao 1998).

Failure Mode and Effect Analysis is a methodical approach to examine a proposed design for possible ways in which failure can occur (Juran 1989, 1993). FMEA consists of (a) identifying and listing modes of failure and the subsequent faults; (b) assessing the probability of these faults; (c) assessing the probability that the faults are detected; (d) assessing the severity of the consequences of the faults; (e) calculating a measure of the risk; (f) ranking the faults on the basis of the risk; (g) attempting to resolve the high-risk problems; and $(\mathrm{h})$ verifying the effectiveness of the action by using a revised measure of risk (Gilchrist 1993). In addition to providing preliminary information on reliability prediction, product and process design, FMEA helps engineers identify potential problems in the product earlier, thereby avoiding costly changes or reworks at later stages (Teng and Ho 1996).

Closely scrutinising quality management reveals that many techniques are based on experience derived from manufacturing tangible 
products. Whether or not quality management practices can be transferred to a service industry delivering intangible services has received considerable attention. Many investigators confer that (a) the service and manufacturing industries differ in terms of the characteristics of quality, (b) different criteria must be used for measuring these industries, and (c) the focus of quality management is rather different than similar (King 1987; DelMar and Sheldon 1988; Kackar 1988; Mitra 1993). The final manufacturing products can be measured objectively, while the quality can be managed by output control. Meanwhile, the deliverables of services are frequently intangible, which is difficult to measure objectively. In addition to the simultaneously delivery and consumption of services, the quality certainly cannot be managed by either output control or process control.

Brophy and Coulling (1996) indicated that with the broad applications in the service sector, the sector has come to the recognition that some aspects of quality management must be approached somewhat differently in the service industry. The most distinguishing characteristic between service and manufacturing industries is that in the former, there is usually a direct interaction between the customer and the service. Libraries and information services have intensive direct interaction and also indirect contact with the customers. Because of the immediacy of the interface, libraries must develop their own framework when integrating quality management approaches into libraries.

\section{Framework of quality management approaches in libraries}

Having different characteristics, library services require special approaches of quality management that go beyond the simple adoption of manufacturing techniques for a product. Quality management related to library functions can be viewed in three phases: before service, during service, and after service. Library services ultimately focus on satisfying the information needs of customers. Before services are provided, the technical service departments should have required books and information resources collected and value-added to enhance their value to the customers. Therefore, the customer-oriented li- brary should regard technical services as resource development system to ensure that every customer has resources properly acquired, organised, displayed or accessed. Having direct contact with customers, the public services should be regarded as information service delivery system and focus on providing information to customers accurately, promptly, and responsively to help customers solve problems, and build up customers' knowledge and ultimately enhance their productivity. Administrative management should be regarded as the service support system to coordinate and allocate resources as well as provide support for technical services and public services to satisfy customers' needs, and to evaluate service performance periodically and to continuously improve service quality. Figure 2 shows the quality management approaches and techniques associated with the stages of service delivery in libraries.

\section{Resource development system}

Largely concerning itself with backstage activities, a resource development system is the off-line preparation for public services and has no direct contact with customers. For services in which the customer need not be present, the service transaction can be de-coupled and standardised. For example, acquisition is considered to be a customised service. Convenient access to Web-accessible public access catalogue (webpac), however, has weaned customers from present interaction with live librarians to interaction via online purchase request and, consequently, only routine order preparation and communication is required. Most activities related to technical services have technical and procedural standards to follow, accounting for why each function is characterised by a high routine and process-orientation. International or domestic rules govern the cataloguing, classification, and information organisation. In addition, standardised practices also exist for acquisition and preservation, e.g. how order requests are to be formulated and transmitted. In fact, many practices in technical services are standardised by actual work routines and formalised based on a detailed and systematic study during library automation. Therefore, the quality management of a resource development system should emphasise the concurrent control of pro- 


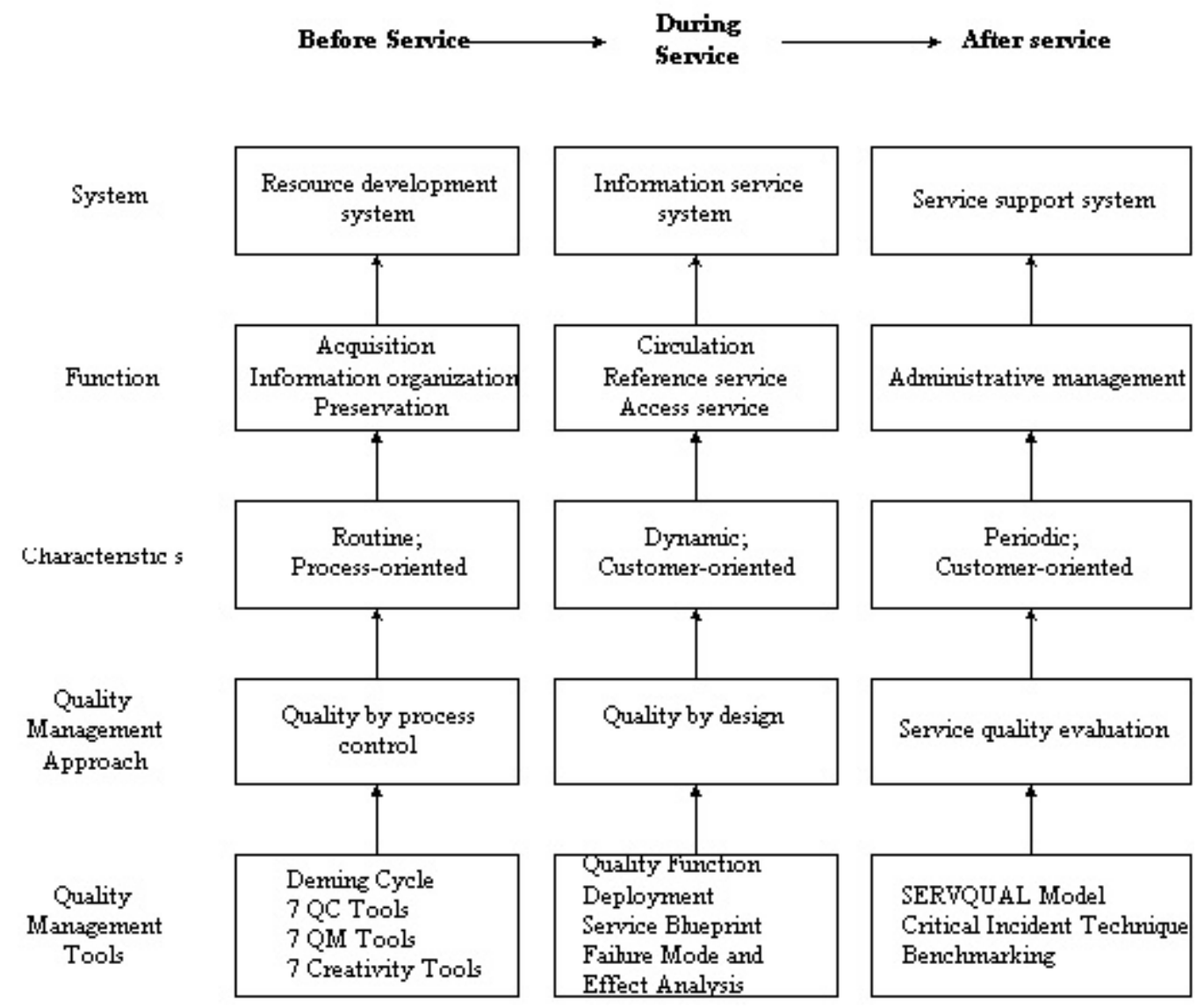

Figure 2: Framework of quality management approaches in libraries

cess to ensure that all books and resources have been accurately collected, accessed and valueadded appropriately. Quality by process control is the best quality management strategy for a resource development system.

Deming's PDSA cycle, together with the seven quality control tools, the seven quality management tools, and the seven creativity tools can be applied in technical services to improve service quality.

The PDSA Cycle (or "the Deming cycle"), as shown in Figure 3, is focused on satisfying customer needs. This requires an attitude of putting the customer first and a belief that this principle is the object of one's work. Implicit in the Deming PDSA approach is that improvement in quality results from continuous, incremental turns of the wheel (Brophy and Coulling 1996).

Seven simple tools - cause-and-effect diagrams, run charts, scatter diagrams, flowcharts, Pareto diagrams, histograms and control charts - have been termed the Seven Quality Control Tools

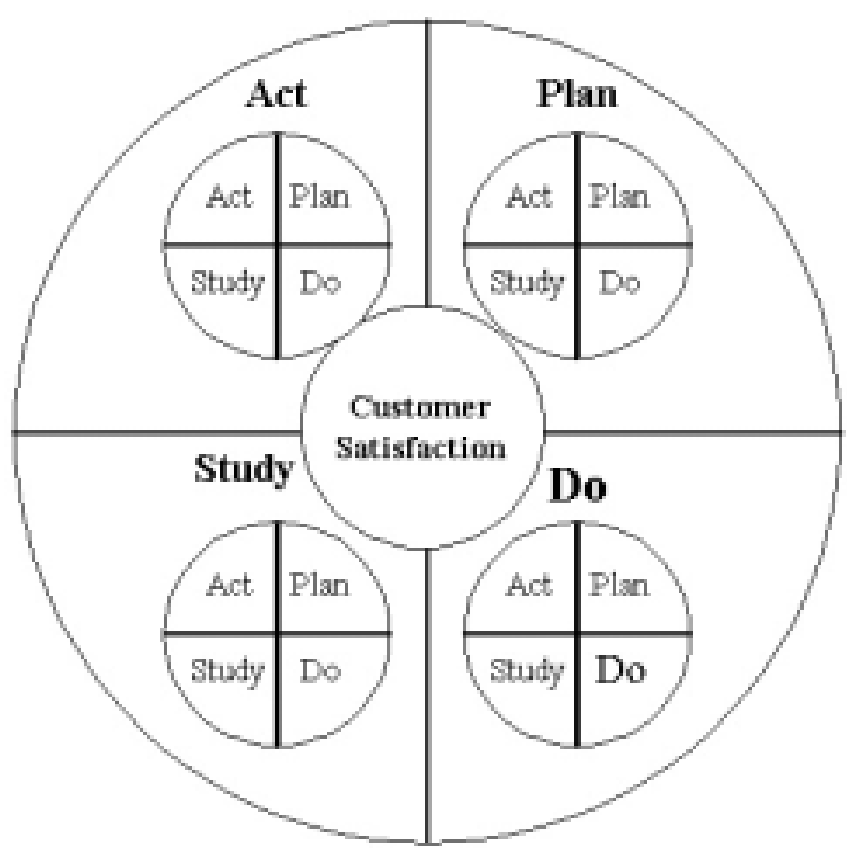

Figure 3: The Deming circle 
Jurow 1993; Brophy and Coulling 1996; GOAL/ QPC 1996). In the early 1970s, as Total Quality Control expanded to service and administrative areas, it became clear that the $7 \mathrm{QC}$ tools were not always appropriate. So, the seven new QC tools or the seven management tools - affinity diagrams, interrelationship digraphs, tree diagrams, matrix diagrams, prioritisation matrixes, process decision program charts, and activity network diagrams - were developed under the leadership of Nyatanni (GOAL/QPC 1996). Among these the affinity diagram is a tool for organising language data. After ideas are brainstormed and written on cards, they are grouped together with similar ideas. A header card is created which captures the meaning of each group of ideas. This is a creative, right brain, activity. The Seven Creativity Tools are problem definition, brainstorming, brainwriting, creative brainstorming, word and picture association, advanced analogies, and the morphological chart (GOAL/QPC 1996).

While the original seven QC tools are oriented towards the analysis of quantitative data, the seven management tools and seven creativity tools are designed to handle unstructured, verbal information in group-base problem-solving or decision-making processes (Johannsen 1992; GOAL/ QPC 1996). All these tools can be used separately or complementarily. For example, the acquisition department can use control chart to evaluate the performance of dealers, and build partnership with the best dealer. The serial department can use the cause-and-effect diagram not only to analyse the causes of missing issues but also use relation diagrams to control the order status of critical serials to ensure the completeness and promptness of serials collection. In addition, the Pareto diagram can be used in the cataloguing department to collect the data on bibliographic verification and copy cataloguing for further analysing the feasibility of enhancing productivity and shortening the processing time.

\section{Information service system}

The information service system is a service delivery system that has direct contact with customers. In circulation, access and reference services, the customer often serves as the co-producer and works with the librarians and the library system to produce a final product which enhances knowl-

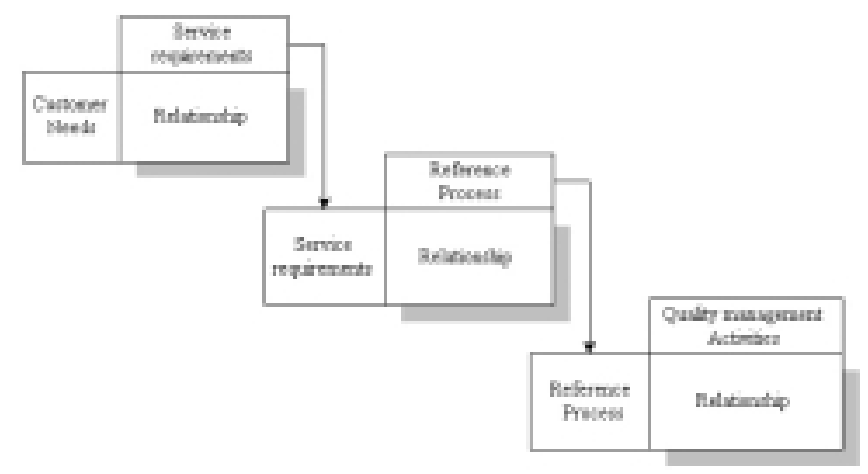

Figure 4: Quality function deployment for reference services

edge, skills, or promotes the enjoyment of leisure activities. The service encounter is always initiated by the customer. Therefore, the major function of an information service system is dynamic and customer-oriented. Because of direct interaction with public service librarians, customers require the service to be done right the first time and to be consistent every time. Consequently, quality by design is the best quality management strategy for information service system. Quality management tools that can be applied are quality function deployment, failure mode and effect analysis, and service blueprinting which is specially designed for effectively managing the service encounter.

Reference service has direct encounters with customers, and the service quality depends highly on the performance of the reference librarians and their interactions with customers. Therefore, the design of reference service can adopt the techniques of quality function deployment. Chang and Hsieh (1996) proposed a modified framework of quality function deployment for reference service, as shown in figure 4 . There are four phases to facilitate communicating service requirements from the customer to the activities related to quality management of reference service delivery. The first phase is to identify the customer's needs and requirements. The second phase is to define the service requirements and design the co-service system so that the right quality is built in from the very beginning of service design. The third phase consists of process planning which is a matter of selecting the co-service process "best" producing what the customer needs. Phase four involves the planning of the quality management activities. It em- 
phasises translating reference processes into quality management activities in order to ensure quality both before and during the reference encounter.

The first task of applying QFD to reference services is to identify customer needs, which are descriptions in the customer's own words of the benefits they want the reference services to provide. The opinions posted on the library web site or BBS (Bulletin Board System), customer complaints, records of reference interviews, previous user studies, and so on, will all contribute to the list of customer needs. In reference services, the primary customer needs might be categorised as "good employees," "right answers" and "nice environment." In order to manage the customer needs, the primary needs need to be structured into a hierarchy. For example, the primary need for "good employee" might be elaborated as "good attitude" and "good skills" in serving customers. And the "good attitude" is subdivided into "kind and polite," "does not have to wait," "assists users in looking up information," and "properly dressed." Each customer need is, then, to be met in terms of professional terminology that is, service requirements. For example, the words "kind and polite" express the customer's concept, but librarians need these words translated into their vocabulary in order to actually build a service delivering standards and quality management activities. In delivering reference service, "kind and polite" may be described in terms of the responsiveness, approachability, attentiveness, and courtesy. The service requirements of reference services translated from customer needs might be grouped into answer, process, and environment, using an Affinity Diagram. For example, the quality of answer might be evaluated according to two perspectives - results and sources. And the quality of source might be evaluated according to the indicators of credibility, acceptability, accessibility and availability. After the service requirements have been identified and prioritised, the most important requirements must be linked to reference process to design the co-service system to satisfy the customer needs.

Circulation and access service is the major contact between the customer and the library, and is usually the starting point for customers to use all other library services. With information networks, most customers can remotely access the webpac or search networked databases. After identifying the availability of certain books or documents, the customer is physically present in the library to check out those books or photocopy the required documents. If the collection or documents needed by the customers are unavailable, the customers can also apply for an interlibrary loan or document delivery service. Encounters between the customer and library are integral and continuous, with each customer possibly encountering many points of services and interacting with varying service facilities and librarians. Therefore, the circulation and access service should be designed by integrating all of the service points to provide seamless services to customers.

The service blueprint is a customer-focused service process analysis tool (Shostack 1987). Figure 5 gives an (incomplete) example of a typical service blueprint for access service. A service blueprint is a detailed map or a flow chart of the service process. However, creating a flow chart can only depict the workflow of internal operations from the perspective of the librarian. Such a flow chart neither provides understanding of the interaction between the librarian and the customer; nor can it integrate these encounter points with related activities that support these encounters. Therefore, the concepts of "line of interaction" and "line of visibility" are used in a service blueprint to improve service encounters. Consequently, the service delivery process can be simultaneously viewed from the perspectives of the librarian and the customer. The line of interaction differentiates actions performed by the customer from actions performed by the librarians. Customer actions are placed above the line. Actions performed by the librarians (regardless of whether they are by access services librarians or by mechanical or automated means) are located below the line. These actions are charted on the service path proceeding from left to right. Along the line of interaction, the encounter points, i.e. the points in the service process where the customer receives the access services, can be easily specified. The line of visibility in a service blueprint distinguishes those processes that are visible to the customer from those that are behind the scenes. This concept facilitates the understanding of the interconnection between "below-the-line" and "abovethe-line" service processes and the recognition 


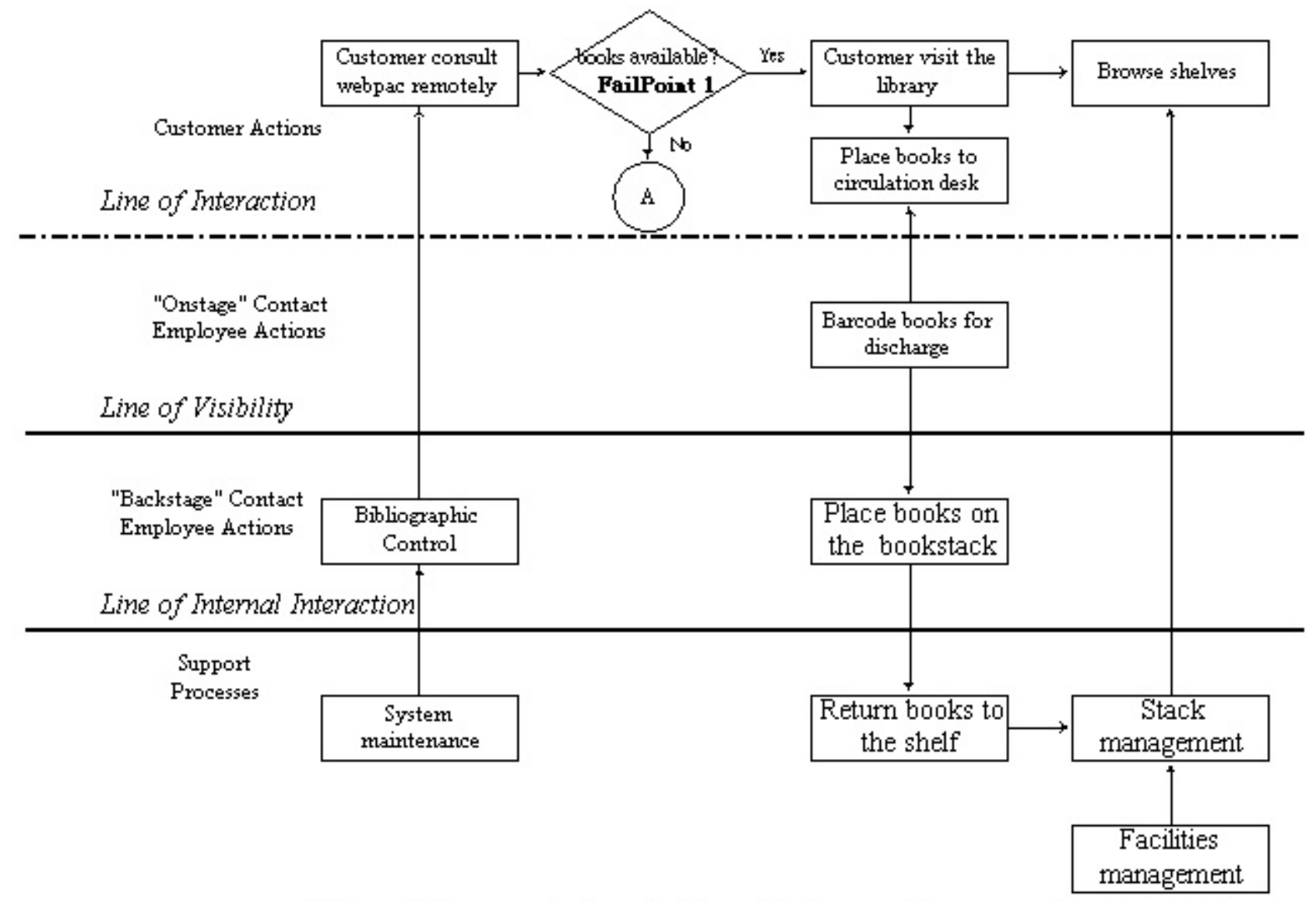

Figure 5: Framework of service blueprint - A case of access service

that the latter processes where the customers' experiences directly depend on the former processes that customers do not experience (Shostack 1984; Kingman-Brundage 1989; George and Gibson 1991; Chang and Hsieh 1998).

The blueprinting exercise also provides librarians with opportunities to identify potential fail points (for example, books unavailable by customer) and, then, use the failure mode and effect analysis to design "foolproof" procedures to avoid such an occurrence, thereby ensuring the delivery of high-quality services.

The purpose of failure mode and effects analysis is to identify all the ways in which a failure can occur, to estimate the effect and seriousness of the failure, and to recommend corrective design actions. An FMEA usually consists of specifying the following information for each critical component: failure mode (how the component can fail), cause of failure, effect on the product or system within which it operates (safety, downtime, repair requirements, tools required), correc- tive action, and comments (Dale, Boaden, Wilcon and McQuater 1998).

\section{Service support system}

The performance of a customer-oriented library should be evaluated on the basis of quality and quantity. Quantitative evaluation in terms of output measure is the basic element of a statistical report, which is mainly prepared for accountability not for improving service. Meanwhile, customer satisfaction significantly contributes to improving service quality. Based on the evaluation results, the service support system should allocate resources to those services that customers deem as having low satisfaction. In practice, the SERVQUAL model, critical incident techniques and benchmarking can be used to evaluate and improve service quality in library services.

Parasuraman, Zeithaml, and Berry (1985) developed a multiple-item scale called SERVQUAL for measuring the five dimensions of service 
quality (i.e. reliability, responsiveness, assurance, empathy, and tangibles). A score for the quality of service is calculated by computing the differences between the ratings that customers assign to paired expectation and perception of each of twenty-two statements. This instrument has been designed and validated for use in a variety of service encounters. In addition, many investigators have adapted the SERVQUAL measures to evaluate the service quality of libraries (White and Abels 1995; Chang and Hsieh 1996; Nitecki 1996; Rowley 1996; Coleman et al. 1997).

Critical incident techniques can be used to analyse the service encounters between the customer and librarians. Customers and employees are interviewed separately to describe their experiences of the service experience. By doing so, the cause of success or failure of the service encounter can be analysed; the critical factors of service encounters can be identified as well. Correspondingly, staff training and development courses can be designed to enhance the capacity of librarians and library instruction. Moreover, information literacy programs can be designed to equip the capacity of customers (Radford 1996, 1999).

For every quality dimension, some organisations (not just libraries) have earned the reputation of being "best in class" and, thus, a benchmark for comparison. Benchmarking, however, involves more than comparing statistics. It also includes visiting the leading organisation to learn firsthand how such outstanding performance has been achieved (Garrod and Kinnell 1997; Robertson and Trahn 1997).

\section{Conclusion}

Manufacturing-based models and techniques for managing quality may be unproductive unless a clear understanding of the particular nature of the service sector is used to re-focus the model and select an appropriate set or sequence of tools or techniques. This article presents a novel framework for incorporating quality management into library and information services. All libraries can select the appropriate techniques for their program with the framework dimensions proposed herein.

Quality management approaches and techniques can help libraries, but do not always guarantee the outcome. Libraries wanting to continuously improve their service quality and completely satisfy customers must create a customeroriented culture in their organisation. First, a framework of total quality management must be established for the library by promoting a quality culture before applying any particular technique. The techniques must be considered as an integral part of the total quality system. Importantly, managers must identify and suggest appropriate methods by analysing issues such as organisational culture, competence, skills, missions, and accessibility of resources and information. Above all, what is required is the support and commitment of senior management to make the application of these approaches and techniques meaningful and useful.

\section{References}

Armstrong, B. 1994. Customer focus - obtaining customer input. In Total Quality Management in Libraries. Rosanna M. O'Neil, ed. Englewood, Colo.: Libraries Unlimited.

Brophy, P and K. Coulling. 1996. Quality Management for Information and Library Managers. London: Aslib Gower.

Buchanan, H.S. and J.G. Marshall. 1996. Benchmarking reference services: step-by-step. Medical Reference Services Quarterly 15 (Spring): 1-13.

Chang, P.L. and P. N. Hsieh. 1996. Using quality function deployment to improve reference services quality. Journal of Library Science 11: 65-96.

Chang, P.L. and P. N. Hsieh. 1996. Evaluating university libraries' service quality: from user's point of view. Bulletin of the Library Association of China 56: 49-68. [Text in Chinese.]

Chang, P.L. and P. N. Hsieh. 1998. Managing quality in access services through blueprinting. Presented at International Symposium on Decision Sciences, Hong Kong, June 13.

Coleman, V., B. Chollett, L. Bair and Y. Xiao. 1997. Toward a TQM paradigm: using SERVQUAL to measure library service quality. College $\mathcal{E}$ Research Libraries 58 (May; 3): 237-45.

Dale, B., R. Boaden, M. Wilcox and R. McQuater. 1998. The use of quality management techniques and tools: an examination of some key issues. International Journal of Technology Management 16 (4/5/6): 305-25.

DelMar, D. and G. Sheldon. 1988. Introduction to Quality Control. St. Paul, MN: West Publishing.

Evans, J.R. and W.M. Lindsay. 1996. The Management and Control of Quality. $3^{\text {rd }}$ ed. St. Paul, MN: West Publishing. 
Garrod, P. and M. Kinnell. 1997. Benchmarking development needs in the LIS sector. Journal of Information Science 23 (2): 111-18.

Garrod, P. and M. Kinnell. 1996. Performance measurement, benchmarking and the UK library and information services sector. Libri 46 (3): 141-8.

George, W.R. and B. E. Gibson. 1991. Blueprinting: a tool for managing quality in service. In Service Quality: Multidisciplinary and Multinational Perspectives, ed. Stephen W. Brown and others. New York: Lexington Books.

Gilchrist, W. 1993. Modeling Failure modes and effects analysis. International Journal of Quality $\mathcal{E}$ Reliability Management 10(5): 16-23.

GOAL/QPC Research. 1996. 7 QC tools, 7 MP tools, 7 creativity tools. GOAL/QPC Research Page. Online. Internet. [4/8/2000]. Available WWW at URL: http://www.goalqpc.com/RESEARCH/

Guinta, L.R. and N. C. Praizler. 1993. The QFD Book. New York: American Management Association.

Johannsen, C.G. 1992. The use of quality control principles and methods in library and information science: theory and practice. Libri 42 (4): 283-95.

Johannsen, C.G. 1996. ISO 9000-managerial approach. Library Management 17 (5): 14-24.

Johannsen, C.G. 1996. Quality management and innovation: findings of a Nordic quality management survey. Libri 45 (September/December; 3/4): 13144.

Juran, J.M. and F. M. Gryna. 1993. Quality Planning and Analysis. New York: McGraw-Hill.

Juran, J.M. 1989. Quality Control Handbook. New York: McGraw-Hill.

Jurow, S. 1993. Tools for measuring and improving performance. Journal of Library Administration 18 (1/2): 113-26.

Jurow, S. and S. B. Barnard, ed. 1993. Integrating total quality management in a library setting. New York: Haworth Press.

Kackar, R.N. 1988. Quality planning for service industries. Quality Progress, 21 (8): 39-42.

King, C.A. 1987. A framework for a service quality assurance system. Quality Progress 20 (9): 27-32.

Kingman-Brundage, J. 1989. The ABCs of service system blueprinting. In Designing a Winning Service Strategy. Chicago: American Marketing Association.

Lam, K. and X. Zhao. 1998. An application of quality function deployment to improve the quality of teaching. International Journal of Quality $\mathcal{E}$ Reliability Management 15 (4): 389-413.

Mitra, A. 1993. Fundamentals of Quality Control and Improvement. New York: Macmillan.
Nitecki, D.A. 1996. Changing the concept and measure of service quality in academic libraries. Journal of Academic Librarianship 22 (May; 3): 181-90.

Parasuraman, A., V. A. Zeithaml and L. L. Berry. 1985. A conceptual model of service quality and its implications for future research. Journal of Marketing 49 (Fall): 41-50.

Parasuraman, A, V. A. Zeithaml and L. L. Berry. 1988. SERVQUAL: a multiple-item scale for measuring consumer perceptions of service quality. Journal of Retailing 64 (Spring; 1): 12-40.

Pitman, G, J. Motwani, A. Kumar and C. H. Cheng. 1996. QFD application in an educational setting: a pilot field study. International Journal of Quality and Reliability Management 13(4): 99-108.

Pritchard, S.M. 1995. Library benchmarking: old wine in new bottles? Journal of Academic Librarianship 21(6): 491-6.

Radford, M.L. 1996. Communication theory applied to the reference encounter: an analysis of critical incidents. Library Quarterly 66(2): 123-37.

Radford, ML. 1999. The reference encounter: interpersonal communication in the academic library. Chicago: Association of College and Research Libraries.

Rahman, S. 1995. Product development stages and associated quality management approaches. The TQM Magazine 7(6): 25-30.

Robbins, S.P. and D. A. De Cenzo. 1998. Fundamentals of Management: Essential Concepts and Applications. Upper Saddle River, NJ: Prentice-Hall International.

Robertson, M. and I. Trahn. 1997. Benchmarking academic libraries: an Australian case study. Australian Academic and Research Libraries 28 (June; 2): 126-41.

Rowley, J. 1996. Managing quality in information services. Information Services \& Use 16 (1): 51-61.

Shostack, G.L. 1984. Designing services that deliver. Harvard Business Review (January-February): 133-9.

Shostack, G.L. 1987. Service positioning through structural change. Journal of Marketing 51 (January): 34-43.

Taipei Municipal Library. 1996. Improving service image: the how-to-do-it manual. Taipei, Taiwan: Taipei Municipal Library. [Text in Chinese]

Teng, S.H. and S. Y. Ho. 1996. Failure mode and effects analysis: an integrated approach for product design and process control. International Journal of Quality E Reliability Management 13 (5): 8-26.

White, M.D. and E. G. Abels. 1995. Measuring service quality in special libraries: lessons from service marketing. Special Libraries 86 (Winter; 1): 36-45.

Zairi, M. and R. Hutton. 1995. Benchmarking: a processdriven tool for quality improvement. The TQM Magazine 7 (3): 35-40. 